\title{
Ionone, Iridoid and Phenylethanoid Glycosides from Ajuga salicifolia
}

Pınar Akbay ${ }^{\mathrm{a}}$, İhsan Çalışs ${ }^{\mathrm{b}}$ Jörg Heilmann ${ }^{\mathrm{a}}$, and Otto Sticher ${ }^{\mathrm{a},{ }^{*}}$

a Department of Applied BioSciences, Institute of Pharmaceutical Sciences, Swiss Federal Institute of Technology (ETH) Zurich, CH-8057 Zürich. Fax: +41-1-6356882.

E-mail: sticher@pharma.anbi.ethz.ch

b Department of Pharmacognosy, Faculty of Pharmacy, Hacettepe University, TR-06100 Ankara

* Author for correspondence and reprint request

Z. Naturforsch. 58c, 177-180 (2003); received September 5/October 7, 2002

From the aerial parts of Ajuga salicifolia (L.) Schreber, a new ionone glycoside (3ß-hydroxy-7,8-dihydro-4-oxo- $\beta$-ionol-9- $O$ - $\beta$-D-glucopyranoside) was isolated, along with the known compounds, corchoionoside $\mathrm{C}, 8-O$-acetylmioporoside, ajugol, harpagide, 8 - $O$-acetylharpagide, lavandulifolioside and leonosides $\mathrm{A}$ and $\mathrm{B}$. This is the first report of the occurrence of ionone glycosides and 8-O-acetylmioporoside in Ajuga species. Ajugol, lavandulifolioside, leonoside $\mathrm{A}$ and $\mathrm{B}$ were isolated for the first time from Ajuga salicifolia. The structures were elucidated by means of 1D-, 2D-NMR spectroscopy, and HR-MALDI mass spectrometry.

Key words: Ajuga salicifolia, Lamiaceae, Ionone Glycosides

\section{Introduction}

In the flora of Turkey, the genus Ajuga (Lamiaceae) is represented by 11 species (Davis, 1982), some of which are traditionally used in wound healing, as diuretic, as well as against diarrhea and high fever (Baytop, 1984). There have been many phytochemical investigations on Ajuga species, focusing mainly on the isolation of phytoecdysteroids and diterpenes and their antifeedant and insect growth inhibiting activities (Camps and Coll, 1993; Camps et al., 1981). Besides our investigations, there was only one report on Ajuga salicifolia (L.) Schreber, concerning the isolation of a diterpene (Bozov et al., 1993), and in an chemotaxonomic investigation, the presence of catechin, flavonoid glycosides, and iridoid glycosides in this plant were described (Litvinenko et al., 1970). Recently, we reported new and novel antileukemic and cytotoxic sterols from the aerial parts of Ajuga salicifolia, which was collected in Ankara, Turkey (Akbay et al., 2002a; Akbay et al., 2002b). Continuing our investigations, we isolated a new ionone glycoside, $3 \beta$-hydroxy-7,8-dihydro-4-oxo- $\beta$-ionol-9- $O$ - $\beta$ D-glucopyranoside (1), together with the known compounds, corchoionoside $\mathrm{C}(\mathbf{2}), 8-O$-acetylmioporoside (3), ajugol (4), harpagide (5), 8- $O$-acetylharpagide (6), lavandulifolioside (7) and leonosides A (8) and B (9). This paper describes the isolation and structure elucidation of these com- pounds and emphasizes on their chemotaxonomic significance.

\section{Material and Methods}

\section{General experimental procedures}

VLC: $R P-18 \mathrm{HL}, 40-63 \mu \mathrm{m}$ (Chemie Uetikon), silica gel 60,40-63 $\mu \mathrm{m}$ (Merck). CC: silica gel 60, 40-63 $\mu \mathrm{m}$ and 63-200 $\mu \mathrm{m}$ (Merck), SephadexLH-20. MPLC: Büchi 681 pump, $45 \times 3.5 \mathrm{~cm}$ Büchi MPLC column packed with $R P-18 \mathrm{HL}, 40-63 \mu \mathrm{m}$. HPLC: Merck-Hitachi L-6200 pump connected to a Rheodyne 7125 Injector, a Merck-Hitachi L4000 UV detector, a Merck D-2500 Chromatointegrator, and a Knauer HPLC column (Spherisorb S10 ODS 2, $10 \mu \mathrm{m} ; 250 \times 20 \mathrm{~mm})$. TLC: Silica gel $60 F_{254}$ precoated aluminium plates $(0.2 \mathrm{~mm}$, Merck), RP-18 $F_{254}$ precoated plates $(0.25 \mathrm{~mm}$, Merck), Detection: $5 \% \mathrm{H}_{2} \mathrm{SO}_{4}$ in EtOH and $1 \%$ vanillin in $\mathrm{EtOH}$ and heating at $100-110{ }^{\circ} \mathrm{C}$ for 5 min. Optical rotation: Perkin-Elmer 241 polarimeter. UV: UVIKON 930 spectrophotometer. HR-MALDI-MS: Ionspec Ultima FTMS spectrometer with 2,5-dihdyroxybenzoic acid (DHB) as matrix. ${ }^{1} \mathrm{H}-,{ }^{13} \mathrm{C}$ NMR, DEPT-135, DEPT-90, $\left[{ }^{1} \mathrm{H},{ }^{1} \mathrm{H}\right]-\mathrm{COSY}, \quad\left[{ }^{13} \mathrm{C},{ }^{1} \mathrm{H}\right]-\mathrm{HSQC}, \quad\left[{ }^{13} \mathrm{C},{ }^{1} \mathrm{H}\right]-$ HMBC and $\left[{ }^{1} \mathrm{H},{ }^{1} \mathrm{H}\right]-\mathrm{NOESY}$ experiments for compound 1 were measured on a Bruker DRX600 at $295 \mathrm{~K}$ (operating at $600.13 \mathrm{MHz}$ for ${ }^{1} \mathrm{H}$, and 
150.92 MHz for $\left.{ }^{13} \mathrm{C}\right) .{ }^{1} \mathrm{H}-,{ }^{13} \mathrm{C} \mathrm{NMR}$ spectra for the other compounds were measured on a Bruker AMX-300 at $295 \mathrm{~K}$ (operating at $300.13 \mathrm{MHz}$ for ${ }^{1} \mathrm{H}$, and $75.47 \mathrm{MHz}$ for ${ }^{13} \mathrm{C}$ ). Chemical shifts $\delta$ were given in ppm and coupling constants $J$ in $\mathrm{Hz}$. The spectra were measured in $\mathrm{CD}_{3} \mathrm{OD}$ for all compounds and also in $\mathrm{D}_{2} \mathrm{O}$ for the iridoids to compare with the literature data. The spectra were referenced against residual non-deuterated solvent.

\section{Plant material}

Ajuga salicifolia (L.) Schreber was collected in Ankara, Beytepe in July 1998. The plant was identified by Prof. Zeki Aytac, Gazi University, Ankara (Turkey). A voucher specimen (HU-98014) was deposited at the Herbarium of the Department of Pharmacognosy, Faculty of Pharmacy, Hacettepe University (Ankara, Turkey).

\section{Extraction and isolation}

The dried and powdered aerial parts $(1 \mathrm{~kg})$ of A. salicifolia were extracted with petroleum ether, dichloromethane, ethyl acetate, methanol and methanol-water $(1: 1 \mathrm{v} / \mathrm{v})$, respectively (sequential percolation with ca. 10-151 of each solvent). After a TLC control, dichloromethane and ethyl acetate extracts were combined $(24 \mathrm{~g})$, and fractionated by VLC (silica gel 60 , hexane $\rightarrow$ ethyl acetate $\rightarrow$ methanol), yielding 5 main fractions. Fr. 4 (2.7 g) was applied to CC (silica gel 60, hexane $\rightarrow$ ethyl acetate $\rightarrow$ methanol). The fraction (600 mg) eluted with EtOAc-MeOH 95:5 was further separated by VLC $\left(R P-18, \mathrm{H}_{2} \mathrm{O}-\mathrm{ACN} 100: 0\right.$ $\rightarrow$ 0:100). Compound $\mathbf{1}(1.6 \mathrm{mg}), \mathbf{2}(2.7 \mathrm{mg})$ and $\mathbf{3}$ $(1.8 \mathrm{mg})$ were isolated from subfraction 2 (38.7 $\mathrm{mg}$ ) by HPLC $\left(R P-18\right.$, flow $5 \mathrm{ml} / \mathrm{min}, \mathrm{H}_{2} \mathrm{O}-$ $\mathrm{ACN}-\mathrm{MeOH}(78: 15: 7))$.

$40 \mathrm{~g}$ of the methanol extract were subjected to VLC $\left(R P-18, \mathrm{H}_{2} \mathrm{O}-\mathrm{MeOH} 100: 0 \rightarrow 0: 100\right)$ to give eight main fractions. Fr. 2 (356 mg), eluted with $5 \% \mathrm{MeOH}$, was subjected to MPLC $\left(\mathrm{H}_{2} \mathrm{O} \rightarrow 70 \%\right.$ $\mathrm{MeOH})$. Two main fractions were purified on a Sephadex LH-20 column (MeOH) yielding compounds 4 (2.7 $\mathrm{mg})$ and $\mathbf{5}(30 \mathrm{mg})$. The same procedure was applied to Fr. 4 (747 mg). Elution with $30 \% \mathrm{MeOH}$ (VLC) furnished compound 6 (20 mg). Fr. 5 (8.4 g), obtained with 50\% MeOH, was submitted to VLC (silica gel, $\mathrm{CH}_{2} \mathrm{Cl}_{2}-$ $\mathrm{MeOH}-\mathrm{H}_{2} \mathrm{O}(90: 10: 1) \rightarrow(40: 60: 4)$. The three frac- tions, rich in phenylethanoids, were further fractioned separately by $\mathrm{CC}$ (silica gel, $\mathrm{CH}_{2} \mathrm{Cl}_{2}-$ $\mathrm{MeOH}-\mathrm{H}_{2} \mathrm{O}$ (90:10:1) $\rightarrow$ (60:40:4) affording 7 (240 mg), 8 (67 mg) and 9 (233 mg).

\section{Spectroscopic data}

$3 \beta$-hydroxy-7,8-dihydro-4-oxo- $\beta$-ionol-9- $O$ - $\beta$-Dglucopyranoside (1) was obtained as a colorless amorphous powder, $[\alpha]_{\mathrm{D}}^{25}-30.0^{\circ}(c 0.1, \mathrm{MeOH})$; UV $(\mathrm{MeOH}) \lambda_{\max }(\log \varepsilon) 248$ (2.80) nm; ${ }^{1} \mathrm{H}$ NMR $\left(\mathrm{CD}_{3} \mathrm{OD}, 600.13 \mathrm{MHz}\right) \delta 4.38(1 \mathrm{H}, \mathrm{d}, J=7.8 \mathrm{~Hz}$, H-1' $), 4.30(1 \mathrm{H}, \mathrm{dd}, J=5.5$ and $13.9 \mathrm{~Hz}, \mathrm{H}-3), 3.93$ $(1 \mathrm{H}, \mathrm{m}, \mathrm{H}-9), 3.89(1 \mathrm{H}, \mathrm{dd}, J=1.9$ and $11.9 \mathrm{~Hz}$, H-6'a), 3.69 (1H, dd, $J=5.4$ and $\left.11.9 \mathrm{~Hz}, \mathrm{H}-6^{\prime} \mathrm{b}\right)$, $3.37\left(1 \mathrm{H}, \mathrm{dd}, J=8.7\right.$ and $\left.9.1 \mathrm{~Hz}, \mathrm{H}-3^{\prime}\right), 3.31(1 \mathrm{H}$, $\left.\mathrm{m}, \mathrm{H}-4^{\prime}\right), 3.28\left(1 \mathrm{H}, \mathrm{m}, \mathrm{H}-5^{\prime}\right), 3.20(1 \mathrm{H}, \mathrm{dd}, J=7.8$ and $\left.9.1 \mathrm{~Hz}, \mathrm{H}-2^{\prime}\right), 2.53(1 \mathrm{H}, \mathrm{m}, \mathrm{H}-7 \mathrm{a}), 2.37(1 \mathrm{H}$, $\mathrm{m}, \mathrm{H}-7 \mathrm{~b}), 2.04(1 \mathrm{H}, \mathrm{dd}, J=5.5$ and $12.6, \mathrm{H}-2 \mathrm{a})$, $1.83\left(3 \mathrm{H}, \mathrm{s}, \mathrm{H}_{3}-13\right), 1.78(1 \mathrm{H}, \mathrm{t}, J=12.6$ and 13.2 , $\mathrm{H}-2 \mathrm{~b}), 1.68$ (2H, m, H-8), $1.32(3 \mathrm{H}, \mathrm{d}, J=6.3$, $\left.\mathrm{H}_{3}-10\right), 1.31$ (3H, s, $\left.\mathrm{H}_{3}-11\right), 1.26\left(3 \mathrm{H}, \mathrm{s}, \mathrm{H}_{3}-12\right) ;{ }^{13} \mathrm{C}$ NMR data $\left(\mathrm{CD}_{3} \mathrm{OD}, 150.92 \mathrm{MHz}\right) \delta 201.5$ (C-4), 167.2 (C-6), 129.7 (C-5), 104.2 (C-1'), 78.3 (C-3'), 77.9 (C-5'), 77.8 (C-9), 75.4 (C-2'), 71.7 (C-4'), 70.4 (C-3), 62.8 (C-6'), 47.0 (C-2), 38.9 (C-1), 36.4 (C-8), 30.0 (C-12), 27.5 (C-7), 25.7 (C-11), 21.9 (C-10), 12.0 (C-13); HR-MALDI-MS (pos. mode): $411.1984[\mathrm{M}+\mathrm{Na}]^{+}$(calculated for $\mathrm{C}_{19} \mathrm{H}_{32} \mathrm{O}_{8} \mathrm{Na}$, 411.1995).

\section{Results and Discussion}

Sequential percolation of the powdered aerial parts of $A$. salicifolia with petroleum ether, dichloromethane, ethyl acetate, methanol and methanol$\mathrm{H}_{2} \mathrm{O}(1: 1 \mathrm{v} / \mathrm{v})$ yielded the crude extracts. After TLC control, dichloromethane and ethyl acetate extracts were combined and subjected to subsequent VLC, CC, and HPLC which led to the isolation of two ionone glycosides $(\mathbf{1}, \mathbf{2})$ and 8 - $O$-acetylmioporoside (3). The fractionation of the methanolic extract by vacuum liquid chromatography (VLC) afforded 8 fractions. The fractions 2,4 and 5 were further fractionated with open column chromatography on silica gel and Sephadex LH-20, MPLC and HPLC on $R P-18$ resulting in the isolation of three iridoid $(\mathbf{4}, \mathbf{5}, \mathbf{6})$ and three phenylethanoid $(\mathbf{7}, \mathbf{8}, \mathbf{9})$ glycosides.

The known compounds $\mathbf{2 - 9}$ were identified as corchoionoside C (2) (Yoshikawa, et al., 1997), 8- 


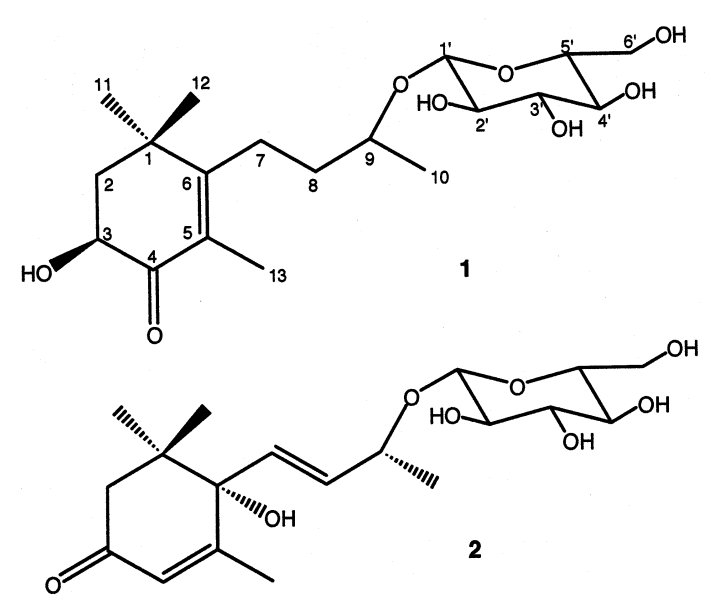

Fig. 1.

$O$-acetylmioporoside (3) (Jacke and Rimpler, 1983; Lammel and Rimpler, 1981), ajugol (4) (Agostini et al., 1982; Nishimura, et al., 1989), harpagide (5) (Yu et al., 1998), 8-O-acetylharpagide (6) (Assaad and Lahloub, 1988; Takeda, et al., 1987), lavandulifolioside (7) (Basaran et al., 1988; Akcos et al., 1998), leonosides A (8) and B (9) (Çalis et al., 1992), respectively, by comparing their ${ }^{1} \mathrm{H}$ and ${ }^{13} \mathrm{C}$ NMR data with previously published data.

Compound 1 was obtained as a colorless amorphous powder. The HR-MALDI-mass spectrum of compound 1 showed a pseudomolecular ion peak at $m / z$ 411.1984 $[\mathrm{M}+\mathrm{Na}]^{+}$, compatible with the molecular formula $\mathrm{C}_{19} \mathrm{H}_{32} \mathrm{O}_{8}$. The ${ }^{1} \mathrm{H}$ - and ${ }^{13} \mathrm{C}$ NMR spectra of $\mathbf{1}$, together with DEPT mode measurement showed the presence of a $\beta$-D-glucopyranosyl moiety from the signals at $\delta_{\mathrm{C}} 104.2$ and $\delta_{\mathrm{H}} 4.38(1 \mathrm{H}, \mathrm{d}, J=7.8)$. They showed also the existence of an aglycone with 13 carbon atoms, which were sorted as 4 methyls, 3 methylenes, 2 methines, 4 quaternary carbons. In ${ }^{1} \mathrm{H}$ NMR spectrum, the signals at $\delta_{\mathrm{H}} 1.31$ and 1.26 as singlets indicated the presence of geminal dimethyl groups $\left(\mathrm{H}_{3}-11\right.$, and $\left.\mathrm{H}_{3}-12\right)$. The resonances at $\delta_{\mathrm{H}} 1.83(\mathrm{~s})$, and $\delta_{\mathrm{H}} 1.32(\mathrm{~d}, J=6.3)$ were attributed to the vinyl methyl $\left(\mathrm{H}_{3}-13\right)$, and to $\mathrm{H}_{3}-10$, respectively. The ${ }^{13} \mathrm{C}$ NMR spectrum displayed two oxymethine $\left(\delta_{\mathrm{C}}\right.$ 70.4, 77.8; C-3, C-9, respectively) signals which were consistent with the resonances at $\delta_{\mathrm{H}} 4.30(\mathrm{dd}$, $J=5.5,13.9 ; \mathrm{H}-3)$, and $\delta_{\mathrm{H}} 3.93(\mathrm{~m} ; \mathrm{H}-9)$ in the ${ }^{1} \mathrm{H}$ NMR spectrum. The chemical shifts of the quater- nary carbons at $\delta_{\mathrm{C}} 201.5,129.7$, and 167.2 exhibited the presence of a carbonyl group conjugated to an endocyclic double bond. ${ }^{1} \mathrm{H},{ }^{1} \mathrm{H}-\mathrm{COSY}$ correlations allowed us to determine the two spin systems of the aglycone. In ${ }^{13} \mathrm{C},{ }^{1} \mathrm{H}-\mathrm{HMBC}$ experiment, the long range correlation between $\mathrm{C}-9$ and $\mathrm{H}-1$ ' showed the position of the glycosidation. The HMBC correlation between $\mathrm{C}-6$ and $\mathrm{H}_{3}-11, \mathrm{H}_{3}-12$, $\mathrm{H}-2, \mathrm{H}-7 \mathrm{a}, \mathrm{H}-7 \mathrm{~b}$ assigned the connection of the two spin systems. The long range correlation between C-4 and $\mathrm{H}-2, \mathrm{H}-3, \mathrm{H}_{3}-13$ confirmed the position of the carbonyl group. The stereochemistry at C-3 was established based on a NOESY experiment. The NOE observed between $\mathrm{H}_{3}-11$ and H-3 showed that these protons were at the same side of the plane. Therefore, the structure of $\mathbf{1}$ was established as 3 $\beta$-hydroxy-7,8-dihydro-4-oxo$\beta$-ionol-9- $O$ - $\beta$-D-glucopyranoside, which is a new ionone glycoside to the literature.

Our phytochemical investigations on the aerial parts of Ajuga salicifolia provided chemotaxonomically significant data. This is the first report of the occurrence of ionone glycosides $(\mathbf{1}, \mathbf{2})$ and 8-Oacetylmioporoside (3) in Ajuga species. To date, 8$O$-acetylmioporoside was only isolated from Clerodendrum spec. (Verbenaceae) (Lammel and Rimpler, 1981). Here is the first report of this compound from the family Lamiaceae. In 1970, Litvinenko et al. reported harpagide (5) and 8-Oacetylharpagide (6) from Ajuga salicifolia. Lavandulifolioside (7) (Çalıs et al., 1992; Didry et al., 1999; Çalıs et al., 1991), and ajugol (4) (Akcos et al., 1998; Çalıs et al., 1991) were previously isolated from many genera in Lamiaceae, the latter also from Ajuga reptans (Guiso et al., 1974). In this paper, compounds 4 and 7, together with leonosides A (8) and B (9) are reported for the first time from Ajuga salicifolia.

\section{Acknowledgments}

We thank Dr. O. Zerbe (Institute of Pharmaceutical Sciences, ETH Zurich) for recording NMR spectra, and to Dr. E. Zass (Institute of Organic Chemisty, ETH Zurich) for performing literature searches. Thanks are also due to Dr. W. Amrein, Mr. R. Häfliger, Mr. O. Greter (Institute of Organic Chemistry, ETH Zurich) for recording mass spectra. Special thanks go to Andreas Miglo and Sara Gobbi for their help in the isolation procedures. 
Agostini A., Guiso M., Marini-Bettolo R., and Martinazzo G. (1982), 5-Deoxylamioside, a new iridoid glucoside from Lamium amplexicaule L., and reassignment of OH-6 configuration of ajugol. Gazz. Chim. Ital. 112, 9-12.

Akbay P., Gertsch J., Çalıs I., Heilmann J., Zerbe O., and Sticher O. (2002a), Novel antileukemic sterol glycosides from Ajuga salicifolia. Helv. Chim. Acta 85, $1930-1942$.

Akbay P., Çalıs I., Heilmann J., and Sticher O. (2002b), Further new sterols from Ajuga salicifolia. J. Nat. Prod. (submitted).

Akcos Y., Ezer N., Ozcelik B., and Abbasoglu U. (1998), Iridoid glucosides from Sideritis lycia Boiss. \& Heldr. and its antimicrobial activities. FABAD Farmasötik Bilimler Dergisi 23, 99-103.

Assaad A. M., and Lahloub M. F. (1988), Iridoid glucoside of Ajuga iva (L.) Schreb (Lamiaceae). Alex. J. Pharm. Sci. 11, 132-135.

Basaran A. A., Calıs I., Anklin C., Nishibe S., and Sticher O. (1988), Lavandulifolioside: a new phenylpropanoid glycoside from Stachys lavandulifolia. Helv. Chim. Acta 71, 1483-1490.

Baytop T. (1984), Therapy with Medicinal Plants (Past and Present). Istanbul University Publications, Istanbul, p. 298, p. 416.

Bozov P. I., Papanov G. Y., Malakov P. Y., De La Torre M. C., and Rodriguez B. (1993), A clerodane diterpene from Ajuga salicifolia. Phytochemistry 34, 1173-1175.

Çalıs I., Basaran A. A., Saracoglu I., and Sticher O. (1991), Iridoid and phenylpropanoid glycosides from Stachys macrantha. Phytochemistry 31, 167-169.

Çalıs I., Ersöz T., Tasdemir D., and Rüedi, P. (1992), Two phenylpropanoid glycosides from Leonurus glaucescens. Phytochemistry, 31, 357-359.

Camps F., and Coll J. (1993), Insect allelochemicals from Ajuga plants. Phytochemistry 32, 1361-1370.
Camps F., Coll J., and Cortel A. (1981), Allelochemicals on insect isolated from Ajuga plants (Labiatae). Rev. Latinoam. Quim. 12, 81-88.

Davis P. H. (1982), Flora of Turkey and the East Aegean Islands, Edinburgh, p. 42.

Didry N., Seidel V., Dubreuil L., Tillequin F., and Bailleul F. (1999), Isolation and antibacterial activity of phenylpropanoid derivatives from Ballota nigra. J. Ethnopharmacol. 67, 197-202.

Guiso M., Marini-Bettolo R., and Agostini A. (1974), Ajugoside and ajugol: structure and configuration. Gazz. Chim. Ital. 104, 25-33.

Jacke G., and Rimpler H. (1983), Distribution of iridoid glycosides in Clerodendrum species. Phytochemistry 22, 1729-1734.

Lammel, G., and Rimpler H. (1981), Iridoide aus Clerodendrum thomsonae Balf. F., Verbenaceae. Z. Naturforsch. 36c, 708-713.

Litvinenko V. I., Zoz I. G., and Sokolov V. S. (1970), Chemotaxonomische Untersuchungen zur Unterfamilie Ajugoideae Benth. der Lamiaceae Lindley. Planta Med. 3, 243-253.

Nishimura H., Sasaki H., Morota T., Chin M., and Mitsuhashi H. (1989), Six iridoid glycosides from Rehmannia glutinosa. Phytochemistry 28, 2705-2709.

Takeda Y., Tsuchida S., and Fujita T. (1987), Four new iridoid glucoside p-coumaroyl esters from Ajuga decumbens. Phytochemistry 26, 2303-2306.

Yoshikawa M., Shimada H., Saka M., Yoshizumi S., Yamahara J., and Matsuda H. (1997), Medicinal Foodstuffs. V. 1) Moroheiya. (1): Absolute stereostructures of corchoionosides $\mathrm{A}, \mathrm{B}$, and $\mathrm{C}$, histamine release inhibitors from the leaves of Vietnamese Corchorus olitorius L. (Tiliaceae). Chem. Pharm. Bull. 45, 464-469.

Yu Y. J., Do J. C., Jung K. Y., Kwon S. Y., and Son K. H. (1998), Studies on the constituents of the herbs of Ajuga multiflora. Kor. J. Pharmacogn. 29, 75-78. 